Penny's area at the time of the Royal Society's first footing on Aldabra, when almost weekly new records were being established for the vast scatter of islands over the western Indian Ocean. The Bahamas have been more completely documented. For a long time there has been a strong population of both breeding and migrant ornithologists - especially on New Providence. And the Galapagos speak for themselves. As perhaps the world's most sensational laboratory of natural evolution, these islands stand in a class of their own and one is left to wonder, as always happens when a deep need is filled, how it was ever possible to manage so long without the book.

The fourth guide is a little different. It is not a Collins, not in fact a Field Guide at all - just a lovely and much needed book. Birds of the Falkland Islands, illustrated by the authors' own photographs, does everything a field guide should do, is valuable and complete. Though $I$ have a possibly self-centred conviction that reference books should be illustrated by artists, and that photographs are the pictorial equivalent of piped music, this is probably as suspect as all generalisations. Behind, beyond, around these photographs of birds lies all the landscape wilderness appeal, the rock and tussac-grass, beaches and cliffs of the windy Falklands - and there are few better places on earth for escape.

KEITH SHACKLETON

\title{
Ocean Wanderers, by R. M. Lockley. David \& Charles and Stackpole Books,
} $£ 5.25$.

Few are so well qualified to write a popular account of the migratory seabirds of the world as R. M. Lockley. During his years on Skokolm he did much to pioneer field studies of seabirds, working not only on their behaviour and breeding biology but, in the case of the Manx shearwater, initiating some of the first tests on their astonishing navigational abilities. Since then, seabird studies have burgeoned dramatically all over the world, and even so skilful a writer faces a stiff task in attempting to summarise current knowledge in 168 pages.

The book falls into two main sections. The first half consists of a series of general chapters on origins and evolution, adaptations to oceanic life, behaviour, food and feeding grounds, navigation, and relations with man. These are immensely readable, conveying the essence of the topic clearly and vividly, though at times, perhaps, the easy prose obscures the complexity of a problem, and on occasion, as in his discussion of marine pollution, even his skill cannot do justice in the limited space available to the many ramifications of the possible dangers. In the second half there are chapters on each of the seven main groups, with some mention of most species involved, but with space to cover only one or two in each section in any detail. Here again, they are often illuminated by his own field experience in Britain and abroad.

This is an exciting and attractive introduction, well illustrated with maps, colour and black-and-white photographs, and many delightful drawings by Robert Gillmor. It underlines the need now for a more comprehensive work, covering fully the mass of new knowledge acquired since 1954 when the author, with James Fisher, wrote the classic Sea-birds, one of the best of the New Naturalist series.

STANLEY CRAMP

The British Oak, edited by M. G. Morris and F. H. Perring. Classey, $£ 6.00$.

This book is the result of a Conference of the Botanical Society of the British Isles, held at the University of Sussex in 1973. It is therefore a collection of papers, twentyone of them, plus an introduction by Dr Eustace Jones, on a wide spread of subjects including the history, folklore, silviculture and utility of oak, Quercus robur and Quercus petraea, as well as all branches of its botany, its teeming inhabitants and their enormously rich ecology. 
Aggregate works of this kind cannot be uniform in quality, but in this case it is the many highs rather than the few lows that invite attention. Most of the papers show massive erudition and will form quite outstanding sources of information for many years to come, in spite of an unfortunate editorial decision, or oversight, which left all but three of the otherwise very useful lists of references in alphabetically random order - most irritating for the enquiring student. What makes the book particularly useful is its index, which contains references not only to oak phenomena in general but to every related and associated species mentioned in the text, though not those in the numerous and lengthy species lists. The latter can be located by looking up group words such as Lichens, Birds or Epiphytes, but sadly not Butterflies, Beetles or Moths, for which there seem to be no lists, though plenty of individual mention.

Although there is nothing new in the concept of oak as a tremendously hospitable and provident wildlife host, this book is the first to bring all the material together and to relate it to the nature of the host itself. It provides a powerful illustration of the FPS principle that preservation of the vegetative habitat is the key to preservation of fauna, though only two of the papers concern themselves directly with silviculture or conservation of oak woodland. In the latter, a tentative and highly arguable case is made for around forty hectares being considered the "minimum area" of oak-bearing wood that is capable of sustaining the whole oakwood ecosystem to the upper levels of the food-chain. In brief, the book is thoroughly worthwhile and deserves the attention of all British naturalists and reference libraries.

\section{H. C. DAWKINS}

\section{The World of the Gray Squirrel, by Frederick S. Barkalow Jr and Monica Shorten. J. B. Lippincott $\$ 5.95$}

The North American grey squirrel, since its introduction a century ago, has largely replaced the native red squirrel in most of England and Wales. It is thus appropriate that the life and times of the grey squirrel should be chronicled by two devoted squirrel watchers - one American and the other English. Both authors have studied the Carolina shadetail in their own and each other's countries, and have presented, in straightforward readable prose which is both serious and wryly humorous, the essence of their own observations, over some 30 years, in the context of cognate research much of which they have stimulated. The procedure of following the life of a female squirrel throughout the year provides opportunities for describing breeding, feeding, early development, pelage changes, vocalisations, movements, scentmarking, and those intricacies of behaviour which need further research for their full elucidation.

From the dense forests of eighteenth-century North America, an abundance of squirrels menaced the settlers' crops, but the squirrels were also a valuable food resource and a legendary training ground for sharp-shooters. Although habitat changes have reduced the numbers, the grey squirrel is still the prime game animal of West Virginia; three and a half million are killed annually in North Carolina, and in the USA as a whole it is the third most important game species.

But the charm of this book is in its felicitous phrasing: "The days of spring are the gray squirrel's salad days ... Woods where the wind has blustered are spiked with buds, and sappy food will soon be plentiful - the sooner the better, for buried food may be getting scarce"; "Now the woods are leafy mazes of sunlight and shadow. The transformation has been going on gradually throughout the spring, but go away for a while and on returning you will find a new world"'.

HARRY V. THOMPSON 